Personalidade Acadêmica Homenageada:

Raymundo Juliano Feitosa (Universidade Federal do Rio Grande do Norte - UFRN)

\title{
NO LIMITE DAS FRONTEIRAS: A MIGRAÇÃO SOB A ÓTICA DA GLOBALIZAÇÃO E DOS DIREITOS HUMANOS
}

\section{ON THE LIMIT OF BORDERS: MIGRATION UNDER THE GLOBALIZATION AND HUMAN RIGHTS VIEW}

\begin{abstract}
AICHA DE ANDRADE QUINTERO EROUD Graduanda do curso de Direito pelo Centro de Ensino Superior de Foz do Iguaçu CESUFOZ. Foz do Iguaçu - PR. E-mail: aichaeroud@hotmail.com

\section{MANOELA MARLI JAQUEIRA}

Doutoranda em Relações Internacionais pela Pontifícia Universidade Católica do Rio de Janeiro (PUC-Rio) e Docente do Centro de Ensino Superior de Foz do Iguaçu (CESUFOZ).Foz do Iguaçu - PR. E-mail: manoelajaqueira@hotmail.com
\end{abstract}

\section{RESUMO}

O conceito de fronteiras, hodiernamente, ultrapassa a compreensão geográfica, rompendo com os antigos paradigmas correlatos à construção dos limites territoriais e da soberania estatal. Na Sociedade global contemporânea, o zelo pela prevalência dos Direitos Humanos e pelo desenvolvimento pacífico mundial com base na cooperação internacional, objetiva, principalmente, sólidas relações internacionais entre os Estados soberanos em nome do Bem Comum. Para tanto, com o fito de assegurar a pacificação e o bom relacionamento entre os Estados Soberanos, criouse documentos internacionais, os quais vinculam os Estados Partes ao seu devido cumprimento. Com efeito, o acordo mútuo entre os países por meio da adesão de tratados ou convenções internacionais causa uma mitigação no conceito de soberania em nome da harmonização internacional e do desenvolvimento econômico, social e 


\section{Personalidade Acadêmica Homenageada:}

Raymundo Juliano Feitosa (Universidade Federal do Rio Grande do Norte - UFRN)

cultural mundial. Nesse cenário, as fronteiras geográficas se desvanecem aos poucos, permitindo maior conexão entre as pessoas de diferentes países, dando ênfase a mobilidade humana. Destaca-se, por assim dizer, a relevância dos Direitos Humanos como importante instrumento internacional no tocante ao direito de migração, ainda mais em tempos de globalização e com o advento da atual crise de refugiados devido as guerras e conflitos ocorridos em alguns países, considerando que a migração ocorre desde os primórdios da civilização. Reconhecendo esse direito, a Declaração Universal de Direitos Humanos trouxe em seu bojo os artigos XIII e XIV, abarcando essa proteção. No mesmo sentido, no ano de 2016, aprovou-se pela Assembleia Geral das Nações Unidas, a Declaração de Nova lorque para Refugiados e Migrantes, o qual abarca o Pacto Global para Refugiados e o Pacto Global para Migração Segura, Ordenada e Regular. O intuito central desse documento é considerar os aspectos humanitários da migração como um direito que visa resguardar a dignidade da pessoa humana, incumbindo aos Estados a sua compreensão dilatada por meio de princípios que regem a ordem internacional, ampliando os debates e soluções sobre a temática como interesse de cunho global. A metodologia empregada para o presente estudo é a pesquisa qualitativa, de recuperação bibliográfica com aportes documentais. Como fundamento dos argumentos expostos, utiliza-se a Declaração Universal dos Direitos Humanos e a Declaração de Nova lorque para Refugiados e Migrantes. A metodologia aplicada tem por espoco alcançar como resultado mediato e imediato, a demonstração da importância do direito de migração sob a égide protecionista dos Direitos Humanos, considerando este como instrumento eficaz na concretização da migração pautada na dignidade da pessoa humana como direito da mobilidade de todos os seres humanos, observando os efeitos da globalização como fator contributivo para as migrações.

PALAVRAS-CHAVE: Migração; Direitos Humanos; globalização.

\section{REFERÊNCIAS}

ALVERNE, Tarin Cristino Frota Mont; OLIVEIRA, Liziane Paixão Silva. Trabalhador 
Personalidade Acadêmica Homenageada:

Raymundo Juliano Feitosa (Universidade Federal do Rio Grande do Norte - UFRN)

migrante e a dificuldade de incorporação da Convenção da OIT e da Convenção da ONU pelo Brasil: possíveis contribuições da Lei de Migrações. Revista Jurídica UNICURITIBA, vol. 4, no, 53. Curitiba: 2018, pp. 611-632. Disponível em: http://revista.unicuritiba.edu.br/index.php/RevJur/article/view/3257/371371771. Acesso em: 02 de jun. de 2019.

ASSEMBLEIA GERAL DA ONU. Declaração Universal dos Direitos Humanos. Nações Unidas, Paris: $1948 . \quad$ Disponível em: https://www.ohchr.org/EN/UDHR/Pages/Language.aspx?LangID=por. Acesso em: 02 de jun. de 2019.

BAUMAN, Zygmunt. Globalização: as consequências humanas. Tradução Marcus Penchel. Rio de Janeiro: Jorge Zahar Editor, 1999. 